\title{
Cigarette Butts Pollution and Environmental Impact - A Review
}

\author{
Aeslina Abdul Kadir ${ }^{1, a}$ and Noor Amira Sarani ${ }^{2, b}$ \\ ${ }^{1}$ Senior Lecturer, Department of Environmental Engineering and Water Resources \\ Universiti Tun Hussein Onn Malaysia (UTHM), \\ 86400 Parit Raja, Batu Pahat Johor, \\ Malaysia \\ 2 Department of Environmental Engineering and Water Resources \\ Universiti Tun Hussein Onn Malaysia (UTHM), \\ 86400 Parit Raja, Batu Pahat Johor, \\ Malaysia \\ aaeslina@uthm.edu.my, ’nramira1987@gmail.com
}

\section{Keywords: Waste Management; Cigarette Butts; Cigarette Filters; Recycling}

\begin{abstract}
Worldwide, cigarette butts (CBs) are among the most common type of litter. The United States Department of Agriculture estimates that in 2004 over 5.5 trillion cigarettes were produced in the world. This is equivalent to an estimated of 1.2 million tonnes of cigarette butt waste per year. These figures are expected to increase by more than $50 \%$ by 2025 according to American Cancer Society, mainly due to an increase in global population. This paper presents a review of the environmental problems associated with CBs, which have been found to be the number one littered item in Australia over the past years. It is estimated 25 to 30 billion filter cigarettes are smoked each year; of these, an estimated 7 billion become litter. The CBs accumulate due to the poor biodegradability of the cellulose acetate filter, and the toxicity constituent trapped within threatens human life, marine ecosystems as well as the environment if not disposed in an appropriate manner. With the increasing concern arising from insufficient landfill sites and the growing environmental awareness about toxic incinerator emissions, there is a critical need for an alternative method for CB waste disposal which is environmentally acceptable.
\end{abstract}

\section{Introduction}

Cigarette waste is one of Australia's most prevalent litter problems. The increasing numbers of butts have become an inland water pollution problem and a consequent important environmental issue. For the past five years, CBs were identified as one of the most littered items in Australia. This finding is consistent with results demonstrated in various reports from Clean Up Australia [1], Keep Australia Beautiful Victoria [2], Keep South Australia Beautiful, New South Wales Litter, Community Change, Victorian Litter Action Alliance (VLAA) [3], Beverage Industry Environment Council (BIEC) [4] and Environmental Protection Agency Victoria (EPAV) [5]. The prominence of $\mathrm{CBs}$ as litter in all the reports and studies emphasises the necessity to identify CBs as a 'waste of concern' that should be prioritised and monitored.

Efforts like campaigns, posters and stickers such as Don't Be A Tosser, Bin Your Butts and The Butt Stops Here, the aluminium kerbside ashtrays that attach to walls, butt receptacles, butt bins, butt bins of high density polyethylene modified with flame retardant, and pole mounted ashtrays have also been installed in some streets identified as being heavily trafficked by smokers to reduce the CBs littering problems. Despite all the campaigns and facilities, the problem has become more prevalent in recent years, particularly with more people smoking outdoors.

\section{Cigarette Butts Filter}

Almost $90 \%$ of all cigarettes are manufactured with cellulose acetate filter tips except for Japan, Venezuela, South Korea and Hungary [6]. Most filter tips (15 to 35mm) [7] are made from plasticlike cellulose acetate. Cellulose acetate is a product with poor biodegradability, which is largely 
determined by the environmental conditions. The degrading rates of cellulose acetate vary from within 1 to 2 months under anaerobic conditions, 6 to 9 months in soil, 12 months in fresh water and 36 months or more under poor conditions [8-10]. The cellulose acetate is packed firmly together to make a filter that looks like cotton and feels like sponge if reviewed by the texture and the appearance of the outer shell [11].

The chemical composition of the cigarette smoke depends on the type of tobacco used, the cigarette paper, the category and the effectiveness of the filter as well as the degree of tip ventilation [12]. Meanwhile, the toxicity and carcinogenic effect of cigarette smoke has been attributed to the carbon monoxide and nicotine as well as other constituents such as nitrogen oxides, hydrogen cyanide, ammonia, some volatile aldehydes and some aromatic hydrocarbons [13]. As for the perforated filters that are normally used in light cigarettes; these significantly decreased carbon monoxide and hydrogen cyanide and also decreased tar, nicotine, nitrosamines volatiles, phenol, polynuclear aromatic hydrocarbons (PAHs), tobacco-specific N-nitrosamines (TSNAs) by more than $50 \%$ [14-15].

Moreover, heavy metals such as aluminium, zinc, lead, selenium, chromium, nickel and cadmium can also be trapped in the filters of the CBs [16-18]. In addition, high permeability cigarette paper also efficiently decreased tar, carbon monoxide, nitrogen oxides, hydrogen cyanide, volatile nitrosamines, TSNAs and benzo(a)pyrene $(\mathrm{BaP})$ in the smoke stream [19].

\section{Toxicity of Cigarette Butts}

The littering problem that arise by habits of smokers 'tossing their butts' has led to the accumulation of CBs in the environment. CB filters release a range of toxic chemicals as they deteriorate. Toxic chemicals trapped in the CB filters can be leached and cause serious damage to the environment [11, 20-21]. There are up to 4,000 chemical components in cigarette smoke, of which 3,000 are in the gas phase and 1,000 in the tar phase. Polycyclic aromatic hydrocarbons (PAHs), N-nitrosamines, aromatic amines, formaldehyde, acetaldehyde, benzene, and toxic metals such as aluminium, zinc, lead, selenium, chromium, nickel and cadmium [16-18] combine to form more than 60 chemicals that are known to be carcinogenic [11, 15, 20-22].

Apart from that, littering of CBs along coastal stretches and in marine ecosystems has also had a significant negative impact. CBs are carried by stormwater into watercourses and ultimately the ocean where the chemicals they contain pose a risk to the organisms of both freshwater and marine environments [23-25]. Studies have publicised several examples of lethal or sub-lethal effects of CB toxicity on marine fauna. Mammals [26-27], birds [28], turtles [29-30] and albenthic organisms [31] are often affected through ingestion, which may affect some of their populations [32]. Unfortunately, only a small number of studies have been conducted examining the impact of CBs on the aquatic environment. These preliminary studies, however, have found that toxic chemicals leached from CBs present a biohazard to freshwater microorganisms at concentrations greater than 0.125 butts per litre of water. In addition, the leachate from the remnant tobacco portion of CBs has been found to be deadly at even smaller concentrations $[12,25]$. Studies have shown that some toxic effects may occur at concentrations of one CB per 4,000 litres [24]. Clearly, this is a significant problem affecting the health of our waterways.

\section{Discussion}

Regulations about solid wastes are becoming more restrictive [33] and the disposal of toxic wastes such as CBs have resulted in growing opposition for suitable landfills especially as the leachability of CBs waste could lead to groundwater contamination if not properly managed [34-35]. In addition, handling toxic substances in landfills is becoming increasingly costly and difficult. Incineration of solid waste also contributes to air pollution [36]. Emission limits into the air may have an influence on the quality of waste to be incinerated and also on the cost of abatement of gaseous emissions [37]. Furthermore, this method also produces ashes that contain large amounts of hazardous materials such as heavy metals that still have to be disposed of [38]. This is expected to 
have a considerable impact on trends to reuse or recycle rather than to incinerate or make use of landfills.

Recycling the CB by itself for other purposes is difficult as there are no easy mechanisms or procedures to assure an efficient and economic separation of the butts, or appropriate treatment of the entrapped chemicals. Therefore, a possible long term solution to deal with $\mathrm{CB}$ waste is to recycle it into building materials and use it for beneficial purposes. One environmentally friendly way is to recycle the CBs into fired clay bricks. This is because the materials used in the brick industry are generally very diverse, as the composition of the clay, which is used as the main raw material, is also naturally variable in its characteristics [39]. The most importantly, the high temperature in clay brick firing process allows volatilisation of dangerous components, changing the chemical characteristics of the materials, and the incorporation of potentially toxic components through fixation in the vitreous phase of the waste utilised [40]. This novel idea could provide a sustainable method to immobilise the toxic chemicals that pose a very high risk towards the environment through either leaching or emissions. Furthermore, the more CB waste is utilised in manufacturing the more the environment, as well as the economy, will benefit, as it will reduce the uncontrolled disposal of the waste and the associated harmful effect on the environment [41-46].

\section{Conclusion}

Based on the above review, it is evident that the littering of CBs is a significantly serious pollution to the environment as the residue of the tobacco, paper and filter with the trapped toxic contaminants, remain in each CB. The increasing amount of this toxic waste raises concern over the traditional disposal methods, which are currently under increasing pressure to change and, thus, there is a significant need for alternative methods to be developed.

\section{References}

[1] Clean Up Australia, Rubbish Report (2008). [Online] Available from: http://www.cleanup.org.au/PDF/au/rubbish-report2008_final.pdf. [Accessed 31st December 2008].

[2] Keep Australia Beautiful Victoria (KABV) (2003) News September/October 2002. [Online]. Available from: http://www.kabv.org.au and http://www.aius.org.au/indicators/documents/Bulletin6EnvirInd.pdf [Accessed $31^{\text {st }}$ December 2008].

[3] Victorian Litter Action Alliance (VLAA) (2004) Environmental Impacts. [Online] Available from: http://www.litter.vic.gov.au/. [Accessed $26^{\text {th }}$ March 2007).

[4] Beverage Industry Environment Council (BIEC) Littering Behaviour Studies. Five: National Benchmark, 2003.

[5] Environmental Protection Authority, Victoria (EPAV) Beach Report Summer 2003-2004. Publication 996, Victoria, Australia, 2005.

[6] U.S Department of Agriculture (USDA), Economic Research Service, Tobacco Situation and Outlook Report. T. B. S, vol. 246, pp. 4, 2000.

[7] Hoffmann, D., Djordjevic, M., V. \& Brunnemann, K. D. Changes in cigarette design and composition over time and how they influence the yields of smoke constituents. Journal Smoking Related Disorders, vol. 6, pp. 9-23, 1995.

[8] Ach, A., Biodegradable plastics based on cellulose acetate. Journal of Macromolecular Science Pure and Applied Chemistry, vol. A30 (9), pp. 733-40, 1993.

[9] Shenstone, P., McDonald, S. \& Mallone, M. (1995) Cigarette Butt Litter. Comissioned by Sydney Water Limited, Ark Research Report, Tobacco Information Centre. [Online] Available from: http://whyquit.com/studies/Butts_Sidney_1995.pdf. [Accessed $1^{\text {st }}$ September 2008].

[10]Brodof, T. A., The mechanisms of cellulose acetate degradation and their relationships to environmental weathering. In: The 50 ${ }^{\text {th }}$ Tobacco Chemists' Research Conference, 19 October, Richmond, Virginia, vol. 50(19), October 1996. 
[11]Register, K., Cigarette butts as litter-toxic as well as ugly?. Bull. Am. Litt. Soc., vol. 25(2), pp. 23-29, 2000.

[12] Borgerding, M. \& Klus, H., Analysis of complex mixtures-Cigarette smoke. Experimental and Toxicologic Pathology, vol. 57, pp. 43-73, 2005.

[13] Hofmann, D. \& Hoffmann, I., Chemistry and toxicology in Cigars: Health Effects and Trends, Bethesda, Md: National Cancer Institute. Smoking and Tobacco Control Monograph, vol. 9, pp. 55-104, 1998.

[14]Hoffmann, D., Djordjevic, M., V. \& Brunnemann, K. D. Changes in cigarette design and composition over time and how they influence the yields of smoke constituents. Journal Smoking Related Disorders, vol. 6, pp. 9-23, 1995.

[15] Hoffmann, D., Hoffmann, I. \& El-Bayoumy, K. The less harmful cigarette: A controversial issue. A tribute to Ernst L. Wynder, Chemical Research in Toxicology, vol. 14 (7), pp. 767-790, 2001.

[16] International Agency for Research In Cancer (IARC), Overall evaluations of carcinogenic risk to humans: An updating of IARC Monographs. Lyons, France, vol. 1-42, pp. 440, 1987.

[17] Chiba, M. \& Masironi, R. Toxic and trace elements in tobacco and tobacco smoke. Bulletin of the World Health Organization, vol. 70 (2), pp. 269-275, 1992.

[18] Kazi, T. G., Jalbani, N., Arain, M. B., Jamali, M. K., Afrid, H. I., Sarfraz R. A. \& Shah, A. Q., Toxic metals distribution in different components of Pakistani and imported cigarette by electrothermal atomic absorption spectrometer. Journal Hazardous Materials, vol. 163(1), pp. 302-307, 2009.

[19]Brunnemann, K. D., Hoffmann, D., Gairola C. G. \& Lee, B. C., Low ignition propensity cigarettes: Smoke analysis for carcinogens and testing for mutagenic activity of the smoke particulate matter. Food and chemical Toxicology, vol. (32), pp. 917-922, 1994.

[20]Hoffmann, D. \& Hoffmann, I., The changing cigarette. Journal Toxic Environmental Health, vol. 50(4), pp. 307-364, 1997.

[21]Li, S., Banyasz, J. L., Parrish, M. E., Lyons-Hart, J. \& Shafer, K. H., Formaldehyde in the gas phase of mainstream smoke. Journal of Analytical and Applied Pyrolysis, vol. 65(2), pp. 137$145,2002$.

[22]Hecht, S. S., Tobacco carcinogens, their biomarkers and tobacco-induced cancer. Nature Reviews, Cancer, vol. 3(10), pp. 733-744, 2003.

[23] Novotny T. E. \& Zhao F., Consumption and production waste: another externality of tobacco use. Tobbaco Control, vol. 8 (1), pp. 75-80, 1999.

[24] Micevska, T., Warne, M. St. J., Pablo, F. \& Patra, R., Variation in and causes of toxicity of cigarette butts to a cladoceran and microtox. Archieves of Environmental Contamination and Toxicology, vol. 50(2), pp. 205-212, 2006.

[25] Novotny, T. E., Lum, K., Smith, E., Wang, V. \& Barnes, R., Cigarette butts and the case for an environmental policy on hazardous cigarette waste. International Journal Environmental Research and Public Health, vol. 6, pp. 1691-1705, 2009.

[26] Secchi, E. R. \& Zarzur, S., Plastic debris ingested by a blainville's beaked whale, Mesoplodon densirostris, washed ashore in Brazil. Aquatic mammals, vol. 25(1), pp. 21-4, 1999.

[27] Henderson, J. R. , A pre- and post-MARPOL Annex V summary of Hawaiian monk seal entanglements and marine debris accumulation in the Northwestern Hawaiian Islands, 19821998. Marine Pollution Bulletin, vol. 42 (7), pp. 584-9, 2001.

[28] Spear, L. B., Ainley, D. G. \& Ribic, C. A., Incidence of plastic in seabirds from the tropical pacific, 1984-1991: relation with distribution of species, sex, age, season, year and body weight. Marine Environmental Research, vol. 40 (2), pp. 123-46, 1995.

[29] Mascarenhas, R., Santos, R. \& Zeppelini, D., Plastic debris ingestion by sea turtle in Paraiba. Brazil. Marine Pollution Bulletin, vol. 49 (4), pp. 354-5, 2004.

[30]Bugoni, L., Krause, L. \& Virginia, P., M. Marine debris and human impacts on sea turtles in Southern Brazil. Marine Pollution Bulletin, vol. 42 (12), pp. 1330-4, 2001. 
[31] Chiappone, M., White, A., Swanson, D. W. \& Miller, S. L. Occurrence and biological impacts of fishing gear and other marine debris in the Florida Keys. Marine Pollution Bulletin, vol. 44 (7), pp. 597-604, 2002.

[32] Laist, D. W., Impacts of marine debris: entanglement of marine life in marine debris including a comprehensive list of species with entanglement and ingestion records. In: Coe, J. M. \& Rogers, D. B. (ed.) Marine Debris: Sources, Impacts and Solutions, New York. Springer. pp. 99-140, 1997.

[33] Basegio, T., Berutti, F., Bernades, A. \& Bergmann, C. P., Environmental and technical aspects of the utilization of tannery sludge as a raw material for clay products. Journal of the European Ceramic Society, vol. 22(13), pp. 2251-2259, 2002.

[34] Ruan, A., Min, H., Peng, X. \& Huang, Z., Isolation and characterization of Pseudomonas sp. strain HF-1, capable of degrading nicotine. Research in Microbiology, vol. 156(5-6), pp. 700 706, 2005.

[35] Yuan, Y., Lu, Z. X., Huang, L. J., Bie, X. M., Lu, F.X. \& Li, Y., Optimization of a medium for enhancing nicotine biodegradation by Ochrobactrum intermedium DN2. Journal of Applied Microbiology, vol. 101(3), pp. 691-697, 2006.

[36] Knox, A., An overview of incineration and EFW technology as applied to the management of municipal solid waste (MSW). ONEIA Energy Subcommittee, University of Western Ontario, 2005.

[37] Hinshaw, G. D. \& Trenholm, A. R., Hazardous waste incineration emissions in perspective. Waste Management, vol. 21, pp. 471-475, 2001.

[38] Narayana, T., Municipal solid waste management in India: From waste disposal to recovery of resources? Waste Management, vol. 29(3), pp. 1163-1166, 2009.

[39]Dondi, M., Marsigli, M., \& Fabbri, B., Recycling of industrial and urban wastes in brick production-A review. Tile \& Brick International, vol. 13 (3), pp. 218, 1997.

[40] Vieira, C. M. F., Andrade, P. M., Maciel, G. S., Vernilli Jr. F. \& Monteiro, S. N., Incorporation of fine steel sludge waste into red ceramic. Material Science and Engineering, vol. 427(1-2), pp. 142-147, 2006.

[41] Abdul Kadir, A. \& Abbas Mohajerani, A., Physico-Mechanical Properties And Leachate Analysis Of Clay Fired Bricks Incorporated With Cigarette Butts. International Conference on Environment (ICENV), Environmental Management and Technologies Towards Sustainable Development, pp. 100, 2008a.

[42] Abdul Kadir, A. \& Abbas Mohajerani, A., Possible Utilization of Cigarette Butts in LightWeight Fired Clay Bricks. Proceedings World Academy Of Science, Engineering And Technology, , ISSN: 2070-3724, Paris, vol. 35 (28), pp. 153-157, September 2008b.

[43] Abdul Kadir, A., Abbas Mohajerani, A., Roddick, F. \& John Buckeridge, J., Density, Strength, Thermal Conductivity and Leachate Characteristics of Light-Weight Fired Clay Bricks Incorporating Cigarette Butts. Proceedings of World Academy Of Science, Engineering And Technology, ISSN: 2070-3724, Japan, vol. 53(170), pp. 1035-1041, May 2009.

[44] Abdul Kadir, A., Abbas Mohajerani, A., Roddick, F. \& John Buckeridge, J., Density, Strength, Thermal Conductivity and Leachate Characteristics of Light-Weight Fired Clay Bricks Incorporating Cigarette Butts, International Journal of Environmental Science and Engineering, vol. 2(4), 2010.

[45] Abdul Kadir, A. \& Abbas Mohajerani, A., Possible Utilization of Cigarette Butts in LightWeight Fired Clay Bricks, International Journal of Environmental Science and Engineering, vol. 2(3), 2010.

[46] Abdul Kadir, A. \& Abbas Mohajerani, A., Recycling Cigarette Butts In Light-Weight Fired Clay Bricks, Journal of Construction Materials, Proceedings of the Institution of Civil Engineers (UK) (Accepted), 2011. 